\title{
Emerging roles of low-density lipoprotein in the development and treatment of breast cancer
}

\author{
Xuefeng Guan ${ }^{1 \dagger}$, Zhuo Liu ${ }^{3 \dagger}$, Zhen Zhao ${ }^{2,6,7 \dagger}$, Xuefeng Zhang ${ }^{4}$, Siteng Tao ${ }^{1}$, Bao Yuan ${ }^{1}$, Jiabao Zhang ${ }^{1}$, \\ Dawei Wang ${ }^{6+}$, Qing Liu Li, $^{2,6^{*}}$ and Yu Ding ${ }^{1 *}$ (i)
}

\begin{abstract}
Breast cancer is a heterogeneous disease with increasing incidence and mortality and represents one of the most common cancer types worldwide. Low-density lipoprotein (LDL) is a complex particle composed of several proteins and lipids, which carries cholesterol into peripheral tissues and also affects the metabolism of fatty acids. Recent reports have indicated an emerging role of LDL in breast cancer, affecting cell proliferation and migration, thereby facilitating disease progression. However, controversy still exists among distinct types of breast cancer that can be affected by LDL. Classical therapeutic approaches, such as radiotherapy, chemotherapy, and lipid-lowering drugs were also reported as affecting LDL metabolism and content in breast cancer patients. Therefore, in this review we summarized and discussed the role of LDL in the development and treatment of breast cancer.
\end{abstract}

Keywords: Breast cancer, LDL, Heterogeneous, Progression, Prognosis, Treatment

\section{Introduction}

Breast cancer is one of the most commonly diagnosed type of cancer, ranking the second-leading cause of cancer-related deaths in women [1]. The pathological role of lipids was indicated when a relationship between obesity and breast cancer was observed [2]. Subsequent studies have shown that obesity may be the cause of a large percentage of breast cancer incidence [3-5] and mortality, implying that abnormal or excessive lipid accumulation may affect breast cancer progression, prognosis, and treatment. Therefore, in this review we summarized and discussed the role of lipids in breast cancer.

\section{Metabolism of low-density lipoprotein-cholesterol}

LDL is a cholesterol-rich lipoprotein particle that carries cholesterol into peripheral tissues, and can be oxidized

\footnotetext{
* Correspondence: 851757626@qq.com; dingyu03@163.com

+Xuefeng Guan, Zhuo Liu, Zhen Zhao and Dawei Wang contributed equally to this work.

${ }^{2}$ Guangdong Provincial Hospital of Chinese Medicine-Zhuhai Hospital, Zhuhai 519015, China

${ }^{1}$ Department of Laboratory Animals, College of Animal Sciences, JiLin University in Changchun of Jilin Province in China, Xian Road 5333\#, Changchun 130062, China

Full list of author information is available at the end of the article
}

to form oxidized LDL. At present, two sources of LDL in the plasma are known: the main source derives from VLDL metabolism, and the second source derives from liver synthesis and subsequent secretion into the circulation [6-8].

LDL is internalized into the cell through receptormediated endocytosis [9]. The covered lacuna on the cell membrane surface is the site of LDL receptor. Once the LDL is bound to its receptor, an endocytic vesicle is formed. Membrane-associated vacuolar $\mathrm{H}+$ ATPase maintains an acidic $\mathrm{pH}$ in the endocytic vesicle by pumping cytosolic $\mathrm{H}+$ into the lumen in an ATP-dependent manner. Once the vesicle is internalized, the receptors return to the plasma membrane, while LDL is delivered to the lysosomes where cholesterol is released, and either exits the lysosomes or is re-esterified by ACAT for accumulation An LDL percentage of $65-70 \%$ in blood plasma depends on LDL receptor clearance, and a small fraction (about $1 / 3$ ) is incorporated by surrounding tissues (including vessel walls). In the event of LDL deficiency, the remaining VLDL is recognized by most LDL receptors, of which most is converted to LDL, thereby increasing the plasma LDL concentration [10-12]. 
Cholesterol is an oil-oil complex that is predominantly produced by the liver. The total amount of cholesterol in the human body is 100 to $200 \mathrm{~g}$. Two-thirds of this is derived from self-synthesis in the body, whereas one-third is derived from food. Cholesterol must be combined with lipoproteins to be transported to various parts in the body. Lipoproteins include LDL and high-density lipoproteins (HDL) [13]. LDL transports cholesterol from the liver to other organs, whereas HDL transports cholesterol from the other organs back to the liver where it is metabolized [14-16]. The metabolic process above is shown in Fig. 1.

\section{LDL increases breast cancer progression}

LDL affects the adhesion of breast cancer cells, favoring cell migration and proliferation. Catarina et al. investigated the function of LDL in MDA-MB-231 breast cancer cells by treating the cells with LDL $(100 \mu \mathrm{g} / \mathrm{mL})$ for 24-48 $\mathrm{h}$, and discovered that breast cancer cell proliferation was increased. Furthermore, LDL induced MDAMB-231 cell migration and decreased adhesion [10, 17, 18]. When comparing the expression of different genes in LDL-treated and control cells at $48 \mathrm{~h}$, overexpression (fold change 21.5 ) of 147 mapped genes (including pERK, pAKT, and pJNK) was observed, whereas 95 mapped genes were down regulated (including CD226, Claudin7, Ocludin, and integrin $\beta 8)[19,20]$. The majority of these genes were involved in pathways regulating cell survival and proliferation. In a subsequent study they confirmed increased phosphorylation of Akt and ERK, but not JNK [10]. While NMT1 inhibition modulates breast cancer progression through stress-triggered JNK pathway [21, 22]. Furthermore, their results indicated that some genes changed their expression without modifying the protein level, whereas for other genes, both the gene expression and corresponding protein expression was changed. Next, they fed mice a high cholesterol diet, which resulted in high LDL levels, and subsequently MDA-MB-231 and 4 T1 cells (another breast cancer cell line) were inoculated in mice, revealing that these cells in high cholesterol diet-fed mice showed a higher proliferative ratio when compared to that of cells inoculated in mice that were fed a normal diet [23-26].

\section{LDL functions as a prognostic indicator for breast cancer}

Vipan et al. evaluated the role of serum lipid content in 100 breast cancer patients and healthy women. Their results revealed that patients with breast cancer possessed high levels of LDL, triglycerides, and total cholesterol when compared to healthy women. No differences were observed in VLDL and HDL levels between patients and healthy women [27]. Catarina et al. evaluated whether plasma LDL-cholesterol levels could be a predicting factor for breast cancer by enrolling 244 breast cancer patients. The results demonstrated that the LDL-cholesterol

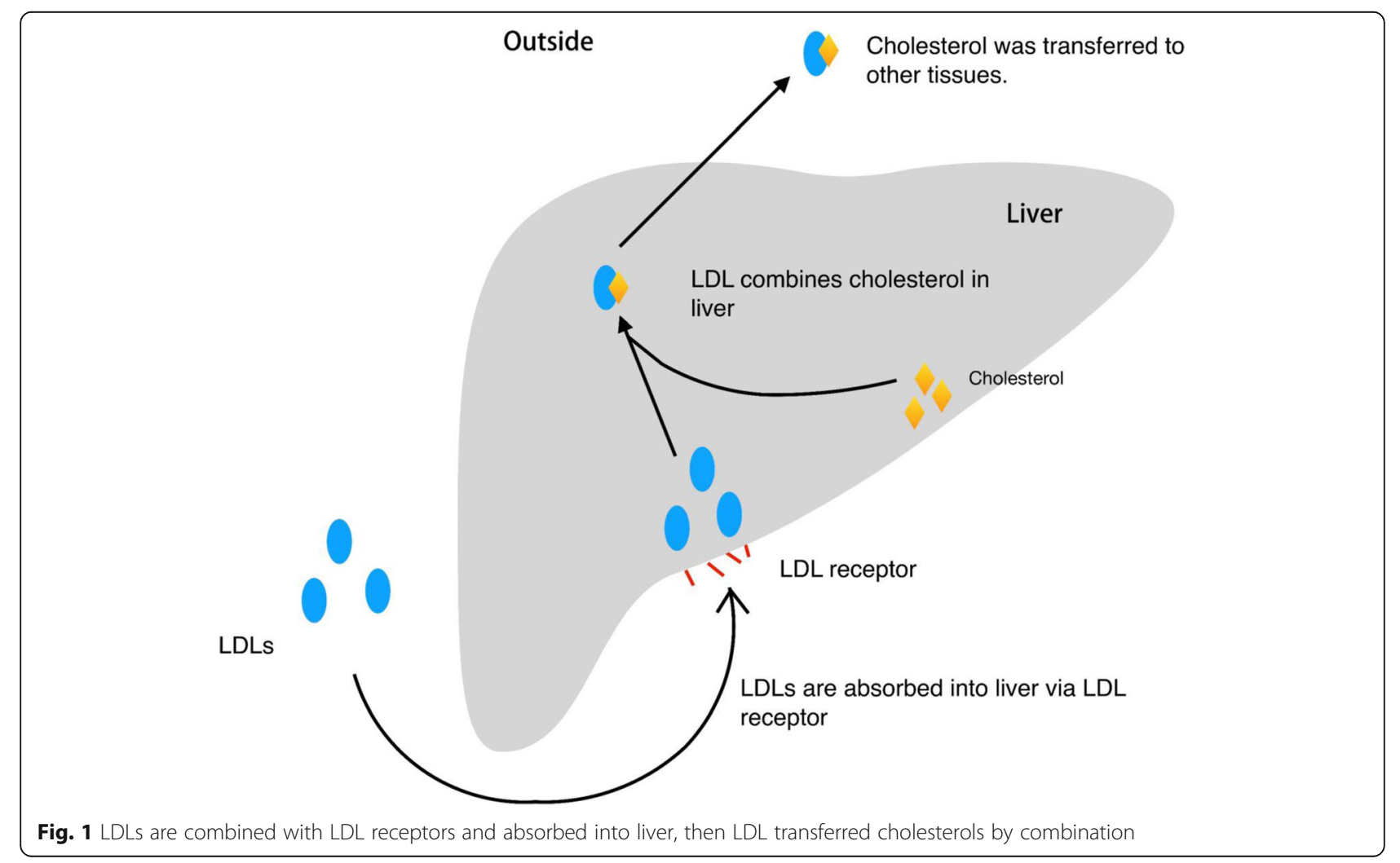


fraction was significantly associated with breast cancer progression, which may be critical in identification and follow-up of high-risk breast cancer patients. Therefore, LDL-cholesterol levels at the time of diagnosis may be considered as a prognostic factor in breast cancer [28].

Besides LDL, Xing et al. studied the effect of preoperative serum triglycerides and HDL-cholesterol levels in the prognosis of breast cancer. Their results showed that a preoperative lower HDL-cholesterol level was a risk factor in breast cancer patients, and decreased levels were significantly associated with worse overall survival $[29,30]$. Paulette et al. evaluated the association between lipid biomarkers and long-term cancer risk, and their on-patients investigation revealed that total cancer risk was significantly lower in the highest quartile of apo A-I and HDL-cholesterol [31].

\section{LDL functions differently in distinct breast cancer types}

$\mathrm{Lu}$ et al. divided LDL into five charge-based subfractions, L1-L5, using anion exchange chromatography, and investigated the relationship between angiogenesis and these subfractions. After treating MCF-7 (luminal-like) cells and MDA-MB-231 (basal like) cells with L1 and L5, they found that L1 and L5 did not effect cell viability of MCF-7 cells, but enhanced the viability of MDA-MB231 cells. Furthermore, they proved that L1 and L5 enhanced anchorage-independent growth, a hallmark of oncogenic transformation, in MDA-MB-231 cells. They also found that L1 had no significant effect on cell migration in MCF-7 cells but increased the migration of MDA-MB-231 cells. In addition, L1 and L5 increased cell migration in other two basal-like breast cancer cell lines, MDA-MB-468 and HS578T. They further discovered that L1 and L5 enhanced the phosphorylation of Akt at S473 in MDA-MB-231 cells, and the phosphorylation of Stat3 at Y705, but not the phosphorylation of Erk, p38, or NF-kB [32].

Caryl et al. investigated the uptake of LDL by breast cancer cells by evaluating LDL receptor expression. They treated MDA-MB-231, MDA-MB-436, MCF-7, and MCF-10A cells with LDL and stained the cells with Oil Red O [33-35]. Their findings revealed that under identical growth conditions, ER-cells, such as MDA-MB-231 and MDA-MB-436 showed elevated Oil Red O-stained lipid droplets when compared to ER+ cell, such as MCF7. Basal and stimulated neutral lipid formation was measured after oleic acid (OA) treatment for $6 \mathrm{~h}$. The results showed that OA treatment increased lipid droplet formation in all cell types. Baseline total triacylglycerol concentration was lower in ER+ MCF-7 cells when compared to ER- MDA-MB-231 and MDA-MB-436 cells, and $\mathrm{OA}$ treatment stimulated total triacylglycerol accumulation to a lesser extent in MCF-7 cells. MCF-7 cells also showed a lower baseline concentration of $\mathrm{CE}$ that did not increase in response to OA. In contrast, ERMDA-MB-231 and MDA-MB-436 cells had a higher baseline $C E$ concentration and showed a dosedependent increase in CE in response to OA. These results demonstrated a difference in both quantity and type of neutral lipid synthesis and storage in basal-like ER- breast cancer cells compared to luminal ER+ cells $[36,37]$. Functions on animal models caused by LDL are summarized in Fig. 2.

\section{LDL influences the effects of fatty acids on breast cancer}

Long-chain polyunsaturated fatty acids (PUFAs) such as omega-3 (n-3) are thought to have tumor-suppressing properties. Specifically, n-3 PUFAs promote the apoptosis of breast cancer cells [38]. and n-3 PUFA-enriched low-density lipoprotein (LDL) has been found to increase the production of syndecan-1 in breast cancer cells and inhibit their development [39]. Moreover, omega-6 (n-6) PUFAs can promote the proliferation and migration of breast cancer through phospholipase D (PLD) and free fatty acid receptor 1 (FFAR1) [40]. It has been found that in MCF-7 and MDA-MB human breast cancer cells, n-3 PUFAs can effectively promote the expression of breast cancer suppressor genes BRCA1 and BRCA2. Interestingly, although n-6 PUFAs have been found to induce tumor proliferation, no effect on the expression of BRCA1 and BRCA2 was found in cells treated with them $[41,42]$. Concurrently, it has been pointed out that n-3 PUFAs had a dose-dependent effect on the fatty acid composition of breast adipose tissue in women with a high risk of breast cancer in a 6-month randomized open-label study involving 48 women with an increased risk of breast cancer [43, 44]. Overall, n-3 PUFAs inhibit breast cancer and n-6 PUFAs promote breast cancer.

N-3 and n-6 PUFAs enter organisms mainly through dietary intake and supplements and are then transported to the tissues by cholesterol, very LDL (VLDL), or LDL, or delivered to the liver via high-density lipoprotein (HDL) [13, 14]. Compared with albumin, more n-3 PUFAs bind to tumor receptors through LDL, thereby inhibiting tumor growth and promoting apoptosis.

In general, LDL has a high concentration of fatty acids [45] However, an excessive intake of n-6 PUFAs can lead to a reduction in LDL receptors, which disables $n-3$ PUFA and promotes the migration and proliferation of tumors. Unfortunately, an improvement in n-3 PUFA intake by healthy subjects does not alter the known effects of dietary saturated fats or n-6 PUFAs on LDL [46] N-3 PUFA consumption reduces the liver's secretion of triglyceride-rich lipoprotein (TRL) and enhances its conversion to LDL. Moreover, they also reduce the concentration of apolipoprotein B (Apo B)-48 TRL by reducing its secretion. It has also been found that high n-6 PUFA 


\begin{tabular}{|c|c|}
\hline $\begin{array}{l}\text { Experimental } \\
\text { Materials }\end{array}$ & Changes in LDL-treated group \\
\hline \multirow{8}{*}{$\begin{array}{l}\text { Breast cancer } \\
\text { cell lines }\end{array}$} & Cells proliferationwas induced. \\
\hline & Cells did notmigrate orinvade. \\
\hline & LDL pre-treated breastcancercells lost theiradhesion to matrix. \\
\hline & Anoikis did not decrease in LDL-treated group. \\
\hline & ER-breast cancercells have visiblymore Oil Red O-staining lipid droplets compared to ER+breast cancercell lines. \\
\hline & Somechemicals likeoleicacid(OA) and paclitaxel-cholesterol complexinfluence the LDLactivities in breast cancercell lines. \\
\hline & Breast cancercell lines have high LDLreceptorexpression. \\
\hline & Various growth factors such as insulin and insulin-like growth factors(IGFs)are associated with obesity-associated breast cancer. \\
\hline Animal Model & tumors of HD fed mice showed a proliferative ratio that was higher than tumors from ND fed mice. \\
\hline
\end{tabular}

Pdigration or invasion was not induced
Breast cancer cell lines(MCF7,
HS578T, MDA-MB-468, MDA-
MB-231 etc)
Fig. 2 We conclude the function that LDL matters to breast cancer cel lines like MDA-MB-231 cells and HTB-20 cells

intake reduces VLDL cholesterol and triglyceride concentrations by the upregulation of lipolysis and the uptake of VLDL [47].

\section{Radiotherapy affects lipid metabolism in breast cancer}

Radiotherapy is a classical therapeutic approach for the treatment of breast cancer. Sana et al. studied how radiotherapy affected lipids metabolism, including serum LDL levels and total cholesterol in breast cancer patients. Their results showed that serum total cholesterol and LDL-cholesterol are significantly decreased after the radiotherapy treatment [48]. However, in another study by Ozmen et al., it was revealed that HDL-cholesterol and total cholesterol levels decreased, while triglycerides and LDL-cholesterol levels increased in patients subjected to radiotherapy compared to healthy controls [49]. This difference may be due to the heterogeneity of the selected subjects in each clinical trial, thus, more investigations should be performed in order to reveal the underlying mechanism involved in the change of lipids during radiotherapy.

Interestingly, not only radiotherapy affects LDL levels, but lipids including LDL also affect the sensitivity of breast cancer cells to radiotherapy. Wolfe et al. found that HDL and LDL have opposite roles compared to VLDL in regulating tumor-initiating cells and sensitivity to radiation in inflammatory breast cancer. VLDL increases and HDL decreases mammosphere formation when compared to untreated SUM 149 and KPL4 cells. In inflammatory breast cancer patients, higher VLDL levels (> $30 \mathrm{mg} / \mathrm{dL}$ ) predicted a lower 5-year overall survival rate, while lower HDL levels $(<60 \mathrm{mg} / \mathrm{dL})$ predicted a lower 5-year overall survival rate [50].Although further studies are needed to confirm and interpret these observations, this study at least discovered a relationship among plasma lipoproteins levels, overall patient response, and radiation resistance in inflammatory breast cancer patients.

\section{Neoadjuvant chemotherapy affects lipid metabolism in breast cancer}

Besides radiotherapy, the effect of neoadjuvant chemotherapy on LDL receptors and LDL receptor-related protein 1 receptor was investigated in patients with locally advanced breast cancer. Changes in LDL receptor expression did not reach a statistical significance due to the small amount of subjects [51]. Both Che et al. [52] and Love et al. [53] studied the influence of tamoxifen in 
the lipid profile of breast cancer patients, and their results revealed that tamoxifen significantly lowers the serum lipid profile of breast cancer patients, including serum LDL-cholesterol and total cholesterol. These results are also supported by a study performed byDziewulska et al [54] Consistently, Chow et al. investigated postmenopausal women with breast cancer, showing that LDL-cholesterol levels in patients treated with exemestane $25 \mathrm{mg}$ daily and celecoxib $400 \mathrm{mg}$ twice-daily progressively decreased, and a statistical significance was observed between the fifth week after operation and preoperative levels [55].

Results from the study by Wasan et al. suggested that letrozole does not significantly alter serum cholesterol, HDL-cholesterol, LDL-cholesterol, triglycerides or Lp(a) in non-hyperlipidemic postmenopausal women with primary breast cancer, although treated with it up to 36 months following at least 5 years of adjuvant tamoxifen therapy [56]. Moreover, Lu et al. showed that anastrozole may lead to an abnormal lipid metabolism in postmenopausal patients with breast cancer. Anastrozole significantly increased the levels of LDLcholesterol, total cholesterol and HDL-cholesterol, and significantly reduced the level of triglycerides [57]. These results suggested that blood lipid levels should be regularly assessed in breast cancer patients under long-term anastrozole treatment, while this assessment seems not relevant in patients under letrozole treatment. The studies mentioned above also suggested that baseline lipid levels in breast cancer patients may affect the effect of neoadjuvant chemotherapy on the lipid profile in breast cancer patients.

\begin{tabular}{|c|c|c|}
\hline $\begin{array}{l}\text { Experimental } \\
\text { object }\end{array}$ & The difference between patients and the normal. & The problems in therapies of breast cancer. \\
\hline \multirow[t]{4}{*}{ Patients } & Breast cancer patients have higher level of LDL. & $\begin{array}{l}\text { RT(Radiotherapy): Carnitine and adiponectin levels } \\
\text { are investigated in breast cancer after radiotherapy. }\end{array}$ \\
\hline & $\begin{array}{l}\text { There was no association of lipid levels in different } \\
\text { grades of breast cancer. }\end{array}$ & $\begin{array}{l}\text { Chemotherapy:LDL receptor expression was studied } \\
\text { after therapy. }\end{array}$ \\
\hline & $\begin{array}{l}\text { Plasma level of LDL-cholesterol can be a predictor } \\
\text { factor of breast cancer. }\end{array}$ & $\begin{array}{l}\text { Drugs:Such as tamoxifen and toremifene are studied } \\
\text { in breast cnacer patients. }\end{array}$ \\
\hline & $\begin{array}{l}\text { Insulin resistance, lipid profile, and visceral adiposity } \\
\text { are associated with increased risk of breast cancer. }\end{array}$ & \\
\hline
\end{tabular}

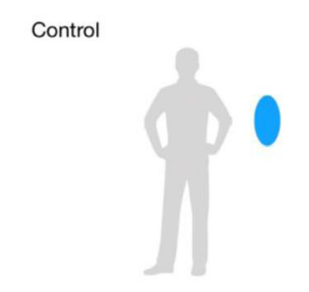

Radiotherapy

Condition after the therapy has to be focused

Breast cancer patients

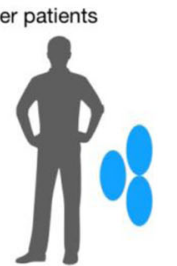

Breast cancer

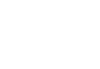

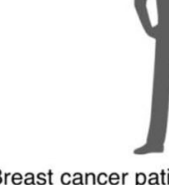

Breast cancer patients had higher level of LDL
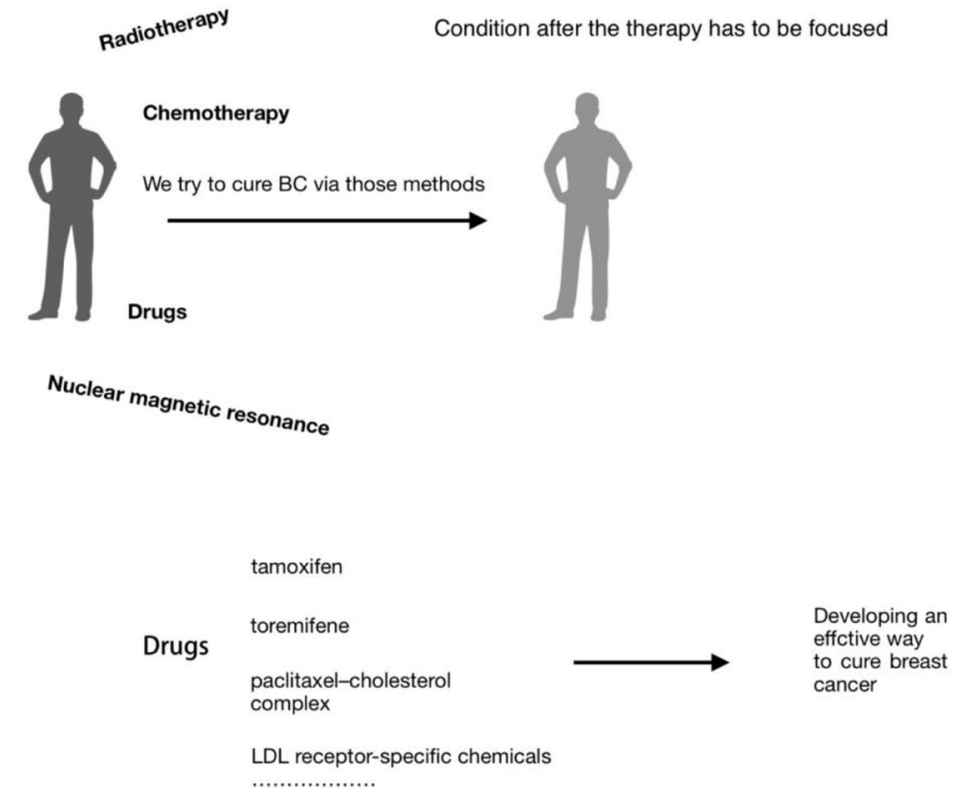

Fig. 3 A lot of researches on breast cancer are made like differing the level between patient group and control group. There are serveral breast cancer therapy methods and more researches on after-therapy conditions need to be investigated 
Table 1 Signaling pathways affected by LDL in the development of breast cancer

\begin{tabular}{|c|c|c|c|}
\hline Pathway and Actived & Moleculars involved & Process regulated & Reference \\
\hline \multirow[t]{2}{*}{ PTEN-PIP3-AKT } & ERK & Proliferation & {$[10,19,20]$} \\
\hline & Akt & Proliferation, Metastasis & \\
\hline \multirow[t]{4}{*}{ DNAM1 } & CD226 & Apoptosis & {$[19,21,22]$} \\
\hline & Claudin7 & Apoptosis, Metastasis & \\
\hline & Ocludin & Metastasis & \\
\hline & Integrin $\beta 8$ & Invasion, Metastasis & \\
\hline \multirow[t]{2}{*}{ JNK } & NMT1 & Growth, Metastasis & {$[10,63]$} \\
\hline & TNF-alpha & Migration & \\
\hline \multirow[t]{5}{*}{ Wnt } & LRP5/6 & Proliferation & {$[36,37,64,65]$} \\
\hline & LRP1 & Proliferation, Metastasis & \\
\hline & SRFP & Proliferation & \\
\hline & MMP9 & Proliferation, Metastasis & \\
\hline & DKK & Proliferation, Metastasis & \\
\hline Y705 & Stat3 & Growth, Transformation & {$[32]$} \\
\hline Rox & miR-21 & Growth & {$[66]$} \\
\hline
\end{tabular}

\section{Lipid-lowering drugs affect lipid metabolism in breast cancer}

Gregory et al. investigated the function of statins on breast cancer. Among adherent statin users, mean LDL levels in subsequent years of follow up was significantly lower in comparison to the 1st year, while mean HDL levels were similar between observation periods [58-60]. Ji et al. evaluated the effect of atorvastatin on breast cancer. The two patient groups (placebo and atorvastatin) were well balanced, with no statistically significant differences in baseline characteristics. However, the statin group showed a significant decrease in cholesterol and LDL levels, suggesting medication involvement [61]. Although many preclinical and epidemiological results support the anticancer effects of statins, epidemiological evidence has not suggested an association between statin use and reduced incidence of breast cancer. Thomas et al. suggested that existing evidence was sufficient to

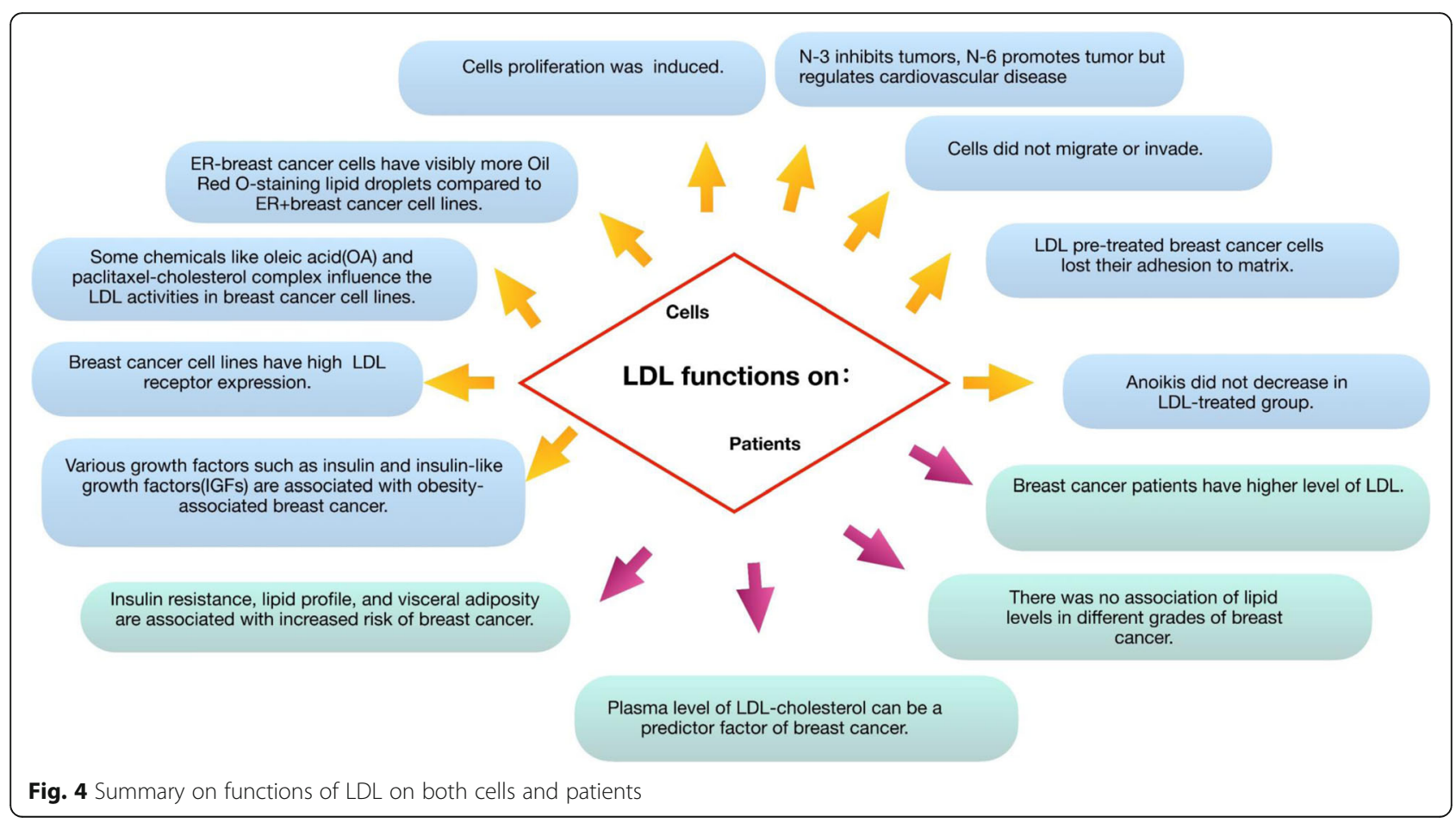


perform a clinical trial on breast cancer using adjuvant therapy with statins, and they claimed that this trial should be performed as soon as possible [62]. The comparison of breast cancer between the patient group and the control group is indicated in Fig. 3.

\section{Summary}

LDL is a lipoprotein particle that carries cholesterol from the liver to peripheral tissues and organs. LDL can be isolated from human peripheral blood by high-speed centrifugation. The treatment of MCF7, 4 T1, HS578T, MDA-MB-468, and MDA-MB-231 breast cancer cell lines with LDL resulted in increased proliferation and migration of certain types of breast cancer cells, and loss of adhesion. The influence on invasion was not remarkable, and anoikis of breast cancer cells was not decreased. Breast cancer patients have higher levels of LDL, which has become a predictor of breast cancer. Classical therapeutic approaches, such as radiotherapy and chemotherapy and their relationship with LDL were investigated resulting influenced and influencing the LDL level. Tamoxifen has an impact on the serum lipid profile including LDL in breast cancer patients, and toremifene is as effective and safe as tamoxifen for advanced breast cancer patients. The use of toremifene may be a great improvement in the process of developing new therapies. A growing body of evidence to support LDL will affect the development of breast cancer through certain signaling pathways and acting cytokines, which summarized in Table 1 and Fig. 4. Moreover, investigating LDL receptor-specific drugs may also provide a promising approach to improve the clinical therapy of breast cancer.

\section{Abbreviations}

AKT: Protein Kinase B; ATP: Adenosine Triphosphate; CD xxx: Cluster Of Differentiation Family; ERK: Extracellular regulated protein kinases; HDL: Highdensity lipoprotein; JNK: c-Jun N-terminal Kinase; LDL: Low-density lipoprotein; OA: Oleic Acid; VLDL: Very Low-density lipoprotein

\section{Acknowledgements}

Not applicable.

\section{Authors' contributions}

The study was designed by QL. The initial search, literature organization and manuscript writing were performed by XG, ZL, ZZ, XZ, ST, BY. Critical comments and typesetting correction on the final version were made by $\mathrm{JZ}$, YD and QL. Manuscript was finalized by YD and QL. All authors have read and revised the manuscript critically.

\section{Funding}

This research was supported by National Natural Science Foundation of China (No. 81603460, to QL), Postdoctoral Science Foundation of China (No. 2015 M581533, to QL); and Jilin Province Science and Technology Development Project (No. 20170623033TC, 20170623035TC, to YD).

\section{Availability of data and materials}

The datasets generated and/or analysed during the current study are available in the NCBI PubMed repository.
Ethics approval and consent to participate

Not applicable.

\section{Consent for publication}

Not applicable.

\section{Competing interests}

The authors declare that they have no competing interests.

\section{Author details}

${ }^{1}$ Department of Laboratory Animals, College of Animal Sciences, JiLin University in Changchun of Jilin Province in China, Xian Road 5333\#, Changchun 130062, China. 'uangdong Provincial Hospital of Chinese Medicine-Zhuhai Hospital, Zhuhai 519015, China. ${ }^{3}$ China-Japan Union Hospital of Jilin University, Changchun 130333, China. ${ }^{4}$ College of Animal Science and Technology, Jilin Agricultural University, Changchun 130118, China. ${ }^{5}$ Department of Immunology, School of Basic Medical Sciences, Fudan University, Shanghai 200032, China. ${ }^{6}$ The 2nd Clinical School of Medicine, Guangdong Provincial Hospital of Chinese Medicine, Guangzhou University of Chinese Medicine, Guangzhou 510120, China. ${ }^{7}$ The 85th Hospital of CPLA, Shanghai 200040, China.

Received: 19 March 2019 Accepted: 19 May 2019

Published online: 10 June 2019

\section{References}

1. Reiner AS, Sisti J, John EM, et al. Breast Cancer family history and contralateral breast Cancer risk in young women: an update from the Women's environmental Cancer and radiation epidemiology study. J Clin Oncol. 2018;36(15):1513-20.

2. Blucher C, Stadler SC. Obesity and breast Cancer: current insights on the role of fatty acids and lipid metabolism in promoting breast Cancer growth and progression. Front Endocrinol (Lausanne). 2017:8:293.

3. Fallone F, Deudon R, Muller C, Vaysse C. Breast cancer, obesity and adipose tissue: a high-risk combination. Med Sci (Paris). 2018;34(12):1079-86.

4. Miller ER, Wilson C, Chapman J, et al. Connecting the dots between breast cancer, obesity and alcohol consumption in middle-aged women: ecological and case control studies. Bmc Public Health. 2018;18(1):460.

5. Bradley CA. Breast cancer: Obesity - tipping the scales of resistance. Nat Rev Cancer. 2018;18(5):265.

6. Kawashiri M, Zhang Y, Usher D, Reilly M, Pure E, Rader DJ. Effects of coexpression of the LDL receptor and apoE on cholesterol metabolism and atherosclerosis in LDL receptor-deficient mice. J Lipid Res. 2001;42(6):94350.

7. Madssen TS, Thune I, Flote VG, et al. Metabolite and lipoprotein responses and prediction of weight gain during breast cancer treatment. Br J Cancer. 2018;119(9):1144-54

8. Akalanka H, Ekanayake S, Samarasinghe K. Could anthropometric and lipid parameters reflect susceptibility to breast Cancer? Comparison of newly diagnosed breast Cancer and apparently healthy women. Asian Pac J Cancer Prev. 2018;19(9):2475-80.

9. Douste-Blazy P. Metabolism of cholesterol: the LDL receptor pathway. Arch Mal Coeur Vaiss. 1987:80:17-22.

10. Dos SC, Domingues G, Matias I, et al. LDL-cholesterol signaling induces breast cancer proliferation and invasion. Lipids Health Dis. 2014;13:16.

11. Cortese C, Turner PR, Marenah CB, et al. Lack of correlation between the maximum low-density lipoprotein (LDL) receptor activity of blood lymphocytes and plasma LDL concentration in normal men. Clin Sci (Lond). 1983;65(1):95-8.

12. Hagander B, Asp NG, Efendic S, Nilsson-Ehle P, Schersten B. Dietary fiber decreases fasting blood glucose levels and plasma LDL concentration in noninsulin-dependent diabetes mellitus patients. Am J Clin Nutr. 1988;47(5): 852-8.

13. Li X, Liu ZL, Wu YT, et al. Status of lipid and lipoprotein in female breast cancer patients at initial diagnosis and during chemotherapy. Lipids Health Dis. 2018;17(1):91.

14. His M, Dartois L, Fagherazzi G, et al. Associations between serum lipids and breast cancer incidence and survival in the E3N prospective cohort study. Cancer Causes Control. 2017;28(1):77-88. 
15. Lofterod T, Mortensen ES, Nalwoga $H$, et al. Impact of pre-diagnostic triglycerides and $\mathrm{HDL}$-cholesterol on breast cancer recurrence and survival by breast cancer subtypes. BMC Cancer. 2018;18(1):654.

16. Samadi S, Ghayour-Mobarhan M, Mohammadpour A, et al. High-density lipoprotein functionality and breast cancer: A potential therapeutic target. J Cell Biochem. 2019:120(4):5756-65.

17. Ma JJ, Jiang L, Tong DY, Ren YN, Sheng MF, Liu HC. CXCL13 inhibition induce the apoptosis of MDA-MB-231 breast cancer cells through blocking CXCR5/ERK signaling pathway. Eur Rev Med Pharmacol Sci. 2018;22(24): 8755-62.

18. Varghese E, Samuel SM, Varghese S, Cheema S, Mamtani R, Busselberg D. Triptolide Decreases Cell Proliferation and Induces Cell Death in Triple Negative MDA-MB-231 Breast Cancer Cells. Biomolecules. 2018;8(4):163.

19. Wang J, Zhang C, Chen K, et al. ERbeta1 inversely correlates with PTEN/ PISK/AKT pathway and predicts a favorable prognosis in triple-negative breast cancer. Breast Cancer Res Treat. 2015;152(2):255-69.

20. Filippi A, Picot T, Aanei CM, et al. Epigallocatechin-3-O-gallate alleviates the malignant phenotype in A-431 epidermoid and SK-BR-3 breast cancer cell lines. Int J Food Sci Nutr. 2018;69(5):584-97.

21. Ge D, Gao J, Han L, et al. Novel effects of sphingosylphosphorylcholine on the apoptosis of breast cancer via autophagy/AKT/p38 and JNK signaling. J Cell Physiol. 2018;234(7):11451-62.

22. Deng L, Gao X, Liu B, et al. NMT1 inhibition modulates breast cancer progression through stress-triggered JNK pathway. Cell Death Dis. 2018; 9(12):1143.

23. Sengupta P, Basu S, Soni S, et al. Cholesterol-tethered platinum II-based supramolecular nanoparticle increases antitumor efficacy and reduces nephrotoxicity. Proc Natl Acad Sci U S A. 2012;109(28):11294-9.

24. Wu L, Liu YY, Li ZX, et al. Anti-tumor effects of penfluridol through dysregulation of cholesterol homeostasis. Asian Pac J Cancer Prev. 2014;15(1):489-94.

25. Sharma S, Mazumdar S, Italiya KS, et al. Cholesterol and Morpholine grafted cationic Amphiphilic copolymers for miRNA-34a delivery. Mol Pharm. 2018; 15(6):2391-402.

26. Mazumdar S, Italiya KS, Sharma S, Chitkara D, Mittal A. Effective cellular internalization, cell cycle arrest and improved pharmacokinetics of Tamoxifen by cholesterol based lipopolymeric nanoparticles. Int J Pharm. 2018;543(1-2):96-106.

27. Kumar V, Singh A, Sidhu DS, Panag KM. A comparitive study to evaluate the role of serum lipid levels in aetiology of carcinoma breast. J Clin Diagn Res. 2015;9(2):C1-3.

28. Rodrigues DSC, Fonseca I, Dias S, Mendes DAJ. Plasma level of LDLcholesterol at diagnosis is a predictor factor of breast tumor progression. BMC Cancer. 2014;14:132

29. Pakzad R, Safiri S. The effect of preoperative serum triglycerides and highdensity lipoprotein-cholesterol levels on the prognosis of breast cancer: Methodological issue. Breast. 2017;36:103-4.

30. Li X, Tang H, Wang J, et al. The effect of preoperative serum triglycerides and high-density lipoprotein-cholesterol levels on the prognosis of breast cancer. Breast. 2017:32:1-6.

31. Chandler PD, Song Y, Lin J, et al. Lipid biomarkers and long-term risk of cancer in the Women's health study. Am J Clin Nutr. 2016;103(6):1397-407.

32. Lu CW, Lo YH, Chen CH, et al. VLDL and LDL, but not HDL, promote breast cancer cell proliferation, metastasis and angiogenesis. Cancer Lett. 2017;388: 130-8.

33. Chajes V, Mahon M, Kostner GM. Influence of LDL oxidation on the proliferation of human breast cancer cells. Free Radic Biol Med. 1996;20(1): 113-20.

34. Antalis CJ, Arnold T, Rasool T, Lee B, Buhman KK, Siddiqui RA. High ACAT1 expression in estrogen receptor negative basal-like breast cancer cells is associated with LDL-induced proliferation. Breast Cancer Res Treat. 2010; 122(3):661-70

35. Gallagher EJ, Zelenko Z, Neel BA, et al. Elevated tumor LDLR expression accelerates LDL cholesterol-mediated breast cancer growth in mouse models of hyperlipidemia. Oncogene. 2017;36(46):6462-71.

36. Chajes V, Mahon M, Kostner GM. Influence of LDL oxidation on the proliferation of human breast cancer cells. Free Radic Biol Med. 1996;20(1):113-20.

37. Boyer-Guittaut M, Poillet $L$, Liang $Q$, et al. The role of GABARAPL1/GEC1 in autophagic flux and mitochondrial quality control in MDA-MB-436 breast cancer cells. Autophagy. 2014;10(6):986-1003.

38. Sun H, Berquin IM, Owens RT, O'Flaherty JT, Edwards IJ. Peroxisome proliferator-activated receptor gamma-mediated up-regulation of syndecan-
1 by n-3 fatty acids promotes apoptosis of human breast cancer cells. Cancer Res. 2008;68(8):2912-9.

39. Sun H, Berquin IM, Edwards IJ. Omega-3 polyunsaturated fatty acids regulate syndecan-1 expression in human breast cancer cells. Cancer Res. 2005;65(10):4442-7.

40. Diaz-Aragon R, Ramirez-Ricardo J, Cortes-Reynosa P, Simoni-Nieves A, Gomez-Quiroz LE, Perez SE. Role of phospholipase D in migration and invasion induced by linoleic acid in breast cancer cells. Mol Cell Biochem. 2019;15:1-4.

41. Bernard-Gallon DJ, Vissac-Sabatier C, Antoine-Vincent D, et al. Differential effects of n-3 and n-6 polyunsaturated fatty acids on BRCA1 and BRCA2 gene expression in breast cell lines. Br J Nutr. 2002;87(4):281-9.

42. Bernard-Gallon DJ, Maurizis JC, Rio PG, Bougnoux P, Bignon YJ. Effects of monounsaturated and polyunsaturated fatty acids (omega-3 and omega-6) on Brca1 protein expression in breast cell lines. J Natl Cancer Inst. 1998; 90(16):1234-5.

43. Yee LD, Lester JL, Cole RM, et al. Omega-3 fatty acid supplements in women at high risk of breast cancer have dose-dependent effects on breast adipose tissue fatty acid composition. Am J Clin Nutr. 2010;91(5): $1185-94$.

44. Lichtenstein AH, Kennedy E, Barrier $\mathrm{P}$, et al. Dietary fat consumption and health. Nutr Rev. 1998;56(5 Pt 2):S3-19, S19-28.

45. Edwards IJ, Berquin IM, Sun $H$, et al. Differential effects of delivery of omega-3 fatty acids to human cancer cells by low-density lipoproteins versus albumin. Clin Cancer Res. 2004;10(24):8275-83.

46. Dias CB, Amigo N, Wood LG, Mallol R, Correig X, Garg ML. Improvement of the omega 3 index of healthy subjects does not alter the effects of dietary saturated fats or n-6PUFA on LDL profiles. Metabolism. 2017;68:11-9.

47. Ooi EM, Watts GF, Ng TW, Barrett PH. Effect of dietary Fatty acids on human lipoprotein metabolism: a comprehensive update. Nutrients. 2015;7(6):4416-25.

48. Shaikh S, Channa NA, Talpur FN, Younis M, Tabassum N. Radiotherapy improves serum fatty acids and lipid profile in breast cancer. Lipids Health Dis. 2017;16(1):92.

49. Ozmen HK, Erdemci B, Askin S, Sezen O. Carnitine and Adiponectin levels in breast Cancer after radiotherapy. Open med (wars). 2017;12:189-94.

50. Wolfe AR, Atkinson RL, Reddy JP, et al. High-density and very-low-density lipoprotein have opposing roles in regulating tumor-initiating cells and sensitivity to radiation in inflammatory breast cancer. Int J Radiat Oncol Biol Phys. 2015;91(5):1072-80.

51. Pires $L A$, Hegg R, Freitas FR, et al. Effect of neoadjuvant chemotherapy on low-density lipoprotein (LDL) receptor and $L D L$ receptor-related protein 1 (LRP-1) receptor in locally advanced breast cancer. Braz J Med Biol Res. 2012;45(6):557-64

52. Lin C, Chen LS, Kuo SJ, Chen DR. Adjuvant tamoxifen influences the lipid profile in breast cancer patients. Breast Care (Basel). 2014;9(1):35-9.

53. Love RR, Newcomb PA, Wiebe DA, et al. Effects of tamoxifen therapy on lipid and lipoprotein levels in postmenopausal patients with node-negative breast cancer. J Natl Cancer Inst. 1990;82(16):1327-32.

54. Dziewulska-Bokiniec A, Wojtacki J, Skokowski J, Kortas B. The effect of tamoxifen treatment on serum cholesterol fractions in breast cancer women. NEOPLASMA. 1994;41(1):13-6.

55. Chow LW, Cheng CW, Wong JL, Toi M. Serum lipid profiles in patients receiving endocrine treatment for breast cancer--the results from the Celecoxib Anti-Aromatase Neoadjuvant (CAAN) Trial. Biomed Pharmacother. 2005;59(Suppl 2):S302-5.

56. Wasan KM, Goss PE, Pritchard PH, et al. The influence of letrozole on serum lipid concentrations in postmenopausal women with primary breast cancer who have completed 5 years of adjuvant tamoxifen (NCIC CTG MA.17L). Ann Oncol. 2005;16(5):707-15.

57. $L u H H, L i ~ Q, X u B H$, et al. Effects of anastrozole on lipid metabolism in Chinese postmenopausal women with breast cancer. Zhonghua Zhong Liu Za Zhi. 2011;33(7):520-5.

58. Calip GS, Boudreau DM, Loggers ET. Changes in adherence to statins and subsequent lipid profiles during and following breast cancer treatment. Breast Cancer Res Treat. 2013;138(1):225-33.

59. Wiwanitkit V. Obesity, HDL and Breast Cancer. Indian J Surg Oncol. 2012;3(4):286.

60. Fan $Y$, Ding $X$, Wang J, et al. Decreased serum HDL at initial diagnosis correlates with worse outcomes for triple-negative breast cancer but not non-TNBCs. Int J Biol Markers. 2015;30(2):e200-7.

61. Ji Y, Rounds T, Crocker A, et al. The Effect of Atorvastatin on Breast Cancer Biomarkers in High-Risk Women. Cancer Prev Res (Phila). 2016;9(5):379-84. 
62. Ahern TP, Lash TL, Damkier P, Christiansen PM, Cronin-Fenton DP. Statins and breast cancer prognosis: evidence and opportunities. Lancet Oncol. 2014;15(10):e461-8.

63. Liang M, Zhang P, Fu J. Up-regulation of LOX-1 expression by TNF-alpha promotes trans-endothelial migration of MDA-MB-231 breast cancer cells. Cancer Lett. 2007:258(1):31-7.

64. Yin P, Wang W, Zhang Z, Bai Y, Gao J, Zhao C. Wnt signaling in human and mouse breast cancer: focusing on Wht ligands, receptors and antagonists. Cancer Sci. 2018;109(11):3368-75.

65. Fayard B, Bianchi F, Dey J, et al. The serine protease inhibitor protease nexin-1 controls mammary cancer metastasis through LRP-1-mediated MMP-9 expression. Cancer Res. 2009;69(14):5690-8.

66. Khaidakov M, Mehta JL. Oxidized LDL triggers pro-oncogenic signaling in human breast mammary epithelial cells partly via stimulation of MiR-21. PLoS One. 2012:7(10):e46973.

\section{Publisher's Note}

Springer Nature remains neutral with regard to jurisdictional claims in published maps and institutional affiliations.

Ready to submit your research? Choose BMC and benefit from:

- fast, convenient online submission

- thorough peer review by experienced researchers in your field

- rapid publication on acceptance

- support for research data, including large and complex data types

- gold Open Access which fosters wider collaboration and increased citations

- maximum visibility for your research: over $100 \mathrm{M}$ website views per year

At BMC, research is always in progress.

Learn more biomedcentral.com/submissions 